\title{
L’expulsió dels moriscos valencians, segons la Relació de Maximilià Cerdà de Tallada
}

\section{The expulsion of the Valencian Moors, accordint to the Relació of Maximilià Cerdà de Tallada}

JOSEP LOZANO

jlozanolerma@gmail.com

Universitat de València

Resum: Aquest article tracta sobre la minoria morisca valenciana i la seva expulsió, a partir de l'estudi d'un text manuscrit de Cerdà de Tallada sobre l'expulsió dels moriscos valencians el 1609. El text, incomplet, conté, tanmateix, nombrosos fets d'interès historiogràfic i és un notable exemple de les cròniques valencianes d'aqueix període del Barroc.

Paraules clau: moriscos, expulsió, València, Maximilià Cerdà de Tallada

Abstract: This article is about the Valencian Moorish minority and their expulsion, based on a study of a manuscript text by Cerdà de Tallada about the expulsion of the Valencian Moors in 1609. The text, which is incomplete, contains, nevertheless, numerous facts of historiographical interest and is a remarkable example of the Valencian chronicles from the Baroque period.

Keywords: moorish, expulsion, Maximilà Cerdà de Tallada 
Josep Lozano. L'expulsió dels moriscos valencians, segons la Relació de Maximilià Cerdà de Tallada

La minoria morisca representava a primeries del segle XVII, aproximadament, un terç del total de la població valenciana (Císcar 2010: 39). La formaven els descendents d'aquells musulmans del Regne de València que van romandre-hi després de la conquesta jaumina del segle XIII. Els quals mai van poder ser assimilats religiosament, ni culturalment, per la societat cristiana que els dominava i els veia com un problema religiós latent a resoldre. Per això i per altres raons, i com ja s'havia fet amb els jueus l'any 1492, foren expulsats a partir del decret de 22 de setembre 1609 publicat a València, en una operació de neteja religiosa de gran envergadura i amb molts trets de genocidi.

Sembla que en aquesta implacable decisió també va influir la Treva dels 12 anys o d'Anvers, signada el 8 d'abril, que comportava una aturada pacífica en la guerra de les Províncies Unides del Nord contra el domini de l'imperi espanyol, iniciada el 1568 per la seua independència. Treva que en el panorama internacional europeu s'havia considerat com un signe de feblesa i de claudicació envers els heretges holandesos i que, en certa manera, l'expulsió dels moriscos podria compensar.

Per altra banda, el meu interès sobre el món morisc es genera quan, farà unes quatre dècades i escaig, prenc la decisió d'escriure la novel la històrica Crim de Germania, sobre la revolta dels agermanats valencians, esdevinguda entre 1519-1522. Més concretament en la prèvia, necessària i obligada recerca de dades sobre aquells fets i els seus personatges i hi descobresc l'existència d'aquella minoria islàmica que havia sigut part actant en la revolta com a carn de tropa del bàndol mascarat o dels nobles, de què n'eren vassalls.

A molts d'aquests moriscos, en fer-los presoners el bàndol contrari, el dels agermanats, els ficaren en sèquies col lectivament $i$ els batejaren a la força, aspergint-los l'aigua baptismal amb ramassos i graneres. Als quals els plantejaven abans la disjuntiva de triar entre el bateig o la mort.

Acabada la Germania amb la derrota del bàndol dels revoltats, les autoritats eclesiàstiques obriren la polèmica sobre la validesa d'aquells batejos. És a dir, si els moriscos batejats a la força, sota l'amenaça de mort, eren cristians de fet o no. Fins que, al capdavall, els il lustres teòlegs argumentaren, amb un cinisme esbalaïdor, que com aquests hi havien pogut escollir entre l'alternativa del bateig obligat o la mort i havien triat el sagrament, calia determinar que eren cristians. Per tant, aquells islàmics batejats en la revolta agermanada, en què els seus senyors cristians consentien o els deixaven fer les seues pràctiques mahometanes, passaren a la condició de cristians nous, amb totes les obligacions i preceptes amb què l'Església Catòlica obligava els seus fidels.

Per a informar-me bé sobre el tema, vaig llegir un llibre de primeries del segle XX, que aleshores es considerava imprescindible en aquesta matèria. Em referesc a l'obra de Pascual Boronat y Barrachina, titulada Los Moriscos Españoles y su expulsión. Estudio Histórico-Crítico, publicada el 1901, amb pròleg de Manuel Danvila y Collado. La qual, al final del seu volum II, compta amb una aclaridora col lecció diplomàtica de 40 documents transcrits sobre els moriscos i una addenda. 
Josep Lozano. L'expulsió dels moriscos valencians, segons la Relació de Maximilià Cerdà de Tallada

Aquest meu interès pel tema morisc ha derivat, o s'ha reflectit, en la meua trajectòria d'escriptor en tres textos: dos narratius i un article.

El primer text narratiu es titula 'Mèmòries de Felip Guzman', que és el curt dietari d'un morisc i forma part de la novel la Crim de Germania, publicada el 1980. En aquella ocasió pretenia d'establir un paral lelisme entre les situacions de marginalitat de la nostra llengua i cultura i les de la llengua $i$ cultura dels moriscos del segle XVI.

El segon és la narració titulada 'El rei Turigi', sobre el morisc Vicent Sumaniar Turigi', natural de Catadau, a qui durant el temps de l'expulsió "alçaren y nomenaren rey", a Cortes, un poble de la vall d'Aiora. $^{2}$

I el tercer és un treball de recerca (Lozano 2001) que vaig fer a la Facultat de Filologia, en el darrer curs de Filologia Catalana, que tenia per objecte la transcripció d'un text fins aleshores inèdit: la Relació de Maximilià Cerdà de Tallada, que vaig acompanyar d'una introducció històrica i d'un estudi lingüístic del text manuscrit sobre grafies, fonètica, morfosintaxi i lèxic.

Aquest document de la dita Relació es troba a l'Arxiu del Reial Convent de Predicadors de València. Ubicació que no ens ha d'estranyar gens, ja que l'orde dels Dominicans o Predicadors va estar vinculada al Regne de València, des dels seus orígens fundacionals en les nostres terres, a l'evangelització i conversió de la població musulmana d'aquí. Arxiu que, tot i haver sigut delmat per la guerra del Francès, la desamortització de Mendizábal i la Guerra Civil de 1936-39, encara compta amb un fons ben interessant de 88 volums de manuscrits.

Pel que fa a la descripció codicològica del document, cal dir que es troba en el volum $77^{3}$; el qual abasta, cronològicament, des del 1609 fins al 1656, i on es troba el report titulat de la Relació de Tallada amb el número 39. Està format per 34 pàgines escrites en català, que va des del 201r fins al 217v, amb algunes errades en la seua ordenació numèrica per la mala enquadernació del volum.

A més a més, el text no té una continuïtat discursiva clara, com s'hi pot apreciar en les indicacions a què ens remet l'autor, quan ens diu que llegim el document que hi ha tot seguit $i$ aquest no hi figura. Per tant és un report incomplet, perquè hi manquen els documents que podrien millor il lustrar-lo. Ens trobem davant d'un text fragmentari, que sembla haver estat copiat més d'una vegada, tret de les primeres planes, on cada fragment està destinat a introduir o glossar un document -que ja he dit adés que no hi consten-, però que tots es refereixen a l'expulsió dels moriscos del Regne de València. Temàtica que li dóna unitat a l'aplec de dades i relats dels fets. I que ben possiblement era la base per a redactar un memorial de greuges del Braç Militar sobre la dita expulsió.

1 En la Relació de Maximilià Cerdà de Tallada figura com 'Turixi'.

2 Text que es publicà en la Revista de la Safor. Anuari del CEIC Alfons el Vell núm. 2, 1' any 2011.

3 És un volum enquadernat amb tapes de pergamí, amb dimensions de 315 per 210 mm, que conté 270 folis, i recull 60 documents sobre els moriscos.

SCRIPTA, Revista internacional de literatura i cultura medieval i moderna, núm. 17 / juny 2021 / pp. 104-116 ISSN: 2340-4841 ·doi:10.7203/SCRIPTA.17.20908 
Josep Lozano. L'expulsió dels moriscos valencians, segons la Relació de Maximilià Cerdà de Tallada

Altrament, atenent-nos als canvis en el tipus de lletra, i als seus trets lingüístics, podem diferenciar tres parts copiades, i no pel mateix transcriptor.

Per altra banda, cal dir que tot i que aquest text es coneix amb el títol abreujat de Relació de Maximilià Cerdà de Tallada, el seu títol complet és el següent: Relació verdadera, molt en particular, de tot lo que ha pasat en la extracció dels moriscos del present Regne de València, y depopulació de aquell, feta y recolta per mi, Maximiliano Cerdá de Tallada, generós, iniciada en lo mes de setembre, any 1609.

Pel que fa a l'autor, hem de dir que no tenim al nostre abast massa dades biogràfiques. Sabem que nasqué entre 1560 i 1565, va casar-se el 1614 amb Maria de l'Esperança Gisbert, i sembla que va morir cec, setze anys després, el 1630. Maximilià era el fill menor d'un doctor en Lleis i jurisconsult prestigiós, Tomàs Cerdà de Tallada (1532-1613), de qui coneixem més dades. Era cavaller i senyor de Cerdanet i fou amic personal dels reis Felip II i Felip III d'Espanya. Va exercir càrrecs a l'Audiència de València, formà part del Consell d'Aragó i està considerat com un precursor del modern penalisme, atés que va escriure i publicar importants obres sobre matèria política, penal i penitenciària: com ara Visita de la Càrcel y de los Presos (1574), Verdadero gobierno de la monarquia de España (1581), Viriloquium de reglas de estado (1604); Repartimiento sumario de la jurisdicció de SM en el Reyno de Valencia (1609), i el Discurso en razón de abreviar pleitos (1613).

En la biografia de Maximilià, el nostre autor, poden distingir dues vessants: una com a escriptor ocasional, cronista d'aquesta Relació, i sobretot poeta, i altra com a home públic. Com a lletraferit participà en les justes poètiques que se celebraven a finals del segle Xvi i primeries del segle XVII a València, dins el corrent de l'Humanisme tardà que féu que es crearen en aquest Regne, i també a Nàpols, acadèmies literàries. Entre aquestes, l'Academia de los Nocturnos que hi hagué a la ciutat del Túria entre els anys 1601 i 1604, que tenia com a seu el palau dels Valeriola de la placeta de Nules.

De la qual Maximilià va ser un dels seus setze membres fundadors, $\mathrm{i}$ on signava les seues composicions poètiques, escrites en castellà, amb el pseudònim de Temeridad. Hi van ser-ne, també, membres d'aquesta Academia, l'historiador Gaspar Escolano i els autors teatrals Gaspar Aguilar i Francesc Tàrrega.

Tanmateix, la producció literària del nostre autor no degué ser massa abundant. És ben significatiu que Vicente Ximeno, en Escritores del reyno de Valencia (1747-48), no li dedique cap entrada. Sols ens informa lacònicament d'ell en la del seu pare, Tomàs Cerdà de Tallada, en què ens diu que Maximilià va ser "Capitán de Caballos, de quien ay dos sonetos al principio del Viriloquium" (Ximeno 1747, I: 232), obra del seu progenitor.

Com a capità de Cavalls de la costa, es dedicava a vigilar el litoral valencià. També se sap que va ser procurador del braç militar en les Corts de 1606; on el nomenaren comissionat davant de Felip III, càrrec que va exercir fins el 1608. A més, en vespres de l'Expulsió participà en les deliberacions del braç militar sobre aquest problema, que tan preocupava els senyors de llocs de moriscos, per les repercussions econòmiques que tindria tal decisió. També perquè a aquest 
Josep Lozano. L'expulsió dels moriscos valencians, segons la Relació de Maximilià Cerdà de Tallada

estament l'havien marginat de la gran operació de desterro dels vassalls propis, que tant podria afectava els seus interessos.

La dita Expulsió dels Moriscos es va fer de forma escalonada entre el 1609 i el 1613, i pel que fa a l'abast cronològic del contingut de la Relació, cal dir que només dóna notícies des d'uns dies abans del 19 de setembre 1609 -dia que el braç militar envia representants a parlar amb el virrei sobre els preparatius que s'estan fent-i fins el 23 d'abril de 1610, en què el nostre cronista constata, ben probablement com a queixa, que la meitat dels terços de Nàpols encara romanien allotjats al Regne.

Tanmateix, la dita Relació ens facilita dades importants i ens parla d'algunes accions, episodis i seqüeles d'aquells fets, com ara:

- La desconfiança i malcontent de l'estament militar, -un dels tres braços de les Corts Forals, la màxima assemblea representativa i normativa del Regne de València- respecte a la decisió real de l'expulsió, ja que no va ser informat prèviament. Decisió que intuien generaria un conflicte entre la política de la monarquia i els interessos dels senyors de vassalls moriscos; perquè aquests es quedarien sense mà d'obra en els pobles de la seua propietat i, per tant, no podrien pagar als censalistes que els havien deixat diners amb la garantia de les rendes d'aquests llogarrets, els quals quedarien deshabitats i improductius. el problema.

- Un altre episodi infructuós va ser l'enviament d'ambaixades al virrei i al rei per a abordar

- La revolta dels moriscos, els quals es feren forts a Guadalest i després a les valls de Laguar i de Gallinera; així com a la Mola de Cortes, on estaran acabdillats per Turigi.

- L'embarcament dels moriscos al port de Vinaròs, el Grau de València, i als ports de Dénia i Alacant.

- La denúncia de la venda de béns mobles dels moriscos, saquejats impunement pels soldats dels terços. La meitat dels quals, segons el bàndol de l'Expulsió, pertanyia als senyors dels dit llocs, però que tot i lamentant-ho no faran res per recuperar-los.

- Ens parla de la reducció o fi de la pensió dels censalistes, perquè l'Expulsió va arruïnar un important sector de la població valenciana de petits inversors.

- I també del batiment de moneda falsa per a entrebancar la vida econòmica del Regne.

Per altres fonts informatives, sabem que el ban, crida o ordre d'expulsió dels moriscos valencians fou publicada pel virrei d'aleshores, marqués de Carazena, Luis Carrillo de Toledo, el 22 de setembre de 1609. Tot i que mesos abans, Carrillo ja havia elaborat un cens per a conèixer la població morisca que havia de ser foragitada del Regne, era un fet del qual que no se'n tenia plena certesa però que 
Josep Lozano. L'expulsió dels moriscos valencians, segons la Relació de Maximilià Cerdà de Tallada

s'intuïa i comportava un ambient de mala maror. Com també que les relacions entre les comunitats cristiana $\mathrm{i}$ islàmica s'hi havien tensat encara més.

Però per a ser més explícit, abordaré, d'una manera succinta, els principals fets que hi figuren en la dita Relació.

Per exemple, dies abans, uns moriscos de Picassent i Alcàsser, que duien planta a vendre a València -ben possiblement verdures-, foren atacats per un gavatx cotxer i altres cristians vells, que els acoltellaren i els furtaren les cavalcadures. Però els moriscos que aconseguiren fugir acudiren a l'auditor. Aquest manà perseguir-los, els empresonà i, dies després, penjaren el gavatx i un altre dels agressors.

El text de Maximilià Cerdà de Tallada comença amb les suspicàcies del braç militar respecte a les intencions, no massa clares, del rei Felip III, com hi palesen les primers línies:

Primerament, havent sabut lo extrenuo braç militar que la Magestat del Rey [...] feya y tenia moltes prevencions de guerra, axí per terra com per mar, totes en lo present recne; considerant que encara que 's deya que era per a la jornada de Alger [...] portava més camí de ser per a la extracció y depopulació dels moriscos.

Malestar que determinarà el síndic Pere Gostans a convocar el braç militar i que s'hi elegisquen representants per a parlar amb el virrei, perquè no els havien informat sobre aquell important afer. Al qual li exposaran "...la notable desconsolació de lo dit braç y estament tenia (...) y que, com si se sospitava, era per la extracció dels moriscos”.

El 19 de setembre de 1609 emprenen el viatge els dos ambaixadors del braç militar cap a Madrid. Tot i que els rumors de l'expulsió són ja grans i preocupants.

Amb data del 21 de setembre sabem, pel Dietari de mossén Pere Joan Porcar (2012, I: 209), que aqueix dia el virrei convoca, a les quatre de la vesprada, els barons, senyors de llocs de cristians nous, diputats i jurats, per a llegir-los "...la lletra de sa real magestat, amb la qual los donà a entendre lo ànimo, y perquè volia llansar los moros de la terra".

El 22 es reuneix la Junta dels tres braços: el Real, l'Eclesiàstic i el Militar, per a elegir ambaixadors per a anar a parlar amb el rei. Se n'elegeixen tres cavallers i tres nobles de la Junta. També s'hi acorda que si hi calia fer-los cap advertència el síndic els la faria, per tal que realitzaren lo faedor.

Però aqueix mateix dia 22 de 1609, es publicava la crida de l'expulsió, que fou lliurada amb lletres a tots els titulats i barons de llocs moriscos. En la qual figura que aquests ja que no tenen mobilitat, han de considerar-se confinats i no poden eixir dels seus pobles, com també que la meitat de llurs béns mobles pertany als seus senyors. 
Josep Lozano. L'expulsió dels moriscos valencians, segons la Relació de Maximilià Cerdà de Tallada

També hi arriba a València don Agustín Mexía, mestre de Camp i del Consell de Guerra de sa majestat, amb càrregues d'or i argent per a les despeses de l'operació de l'embarcament. A més a més, hi ha moviments militars: a Dénia desembarquen don Pedro de Toledo, general de la mar Mediterrània, i don Luis de Faxardo, general de la mar Oceana, amb 6 galions, 7 llanxes, 27 naus, 11 galeres de Sicília, les de Nàpols i Llombardia, i les d'Espanya, amb els terços de Portugal.

Per terra, a la frontera de Castella amb el Regne de València hi havia allotjada molta gent de cavalleria i infanteria i, al Regne d'Aragó, molta gent quintada, com també es mobilitzen els terços i companyies de la milícia efectiva del Regne, de les parts de tramuntana, llevant i ponent. I ls jurats de València ordenen moldre 1700 sacs de blat, per a que "fetes farines es tinguesen en depòsit y custodiats", per si els moriscos desbarataven castells i els assuts de les sèquies, i no es pogués moldre. A fi que hi hagués farina per a 5 o 6 dies.

El 24 de setembre de 1609, es publica una nova crida, en la qual es declara que els moriscos podien vendre, abans d'embarcar-se, tots els béns immobles. Aquest dia també hi ha alguns enfrontaments amb els castells i els assuts de les sèquies de València.

El 25 de setembre, ja n’hi ha una gran mobilització. El virrei encarrega a Tomàs Cerdà de Tallada, de la guàrdia del palau reial, cavaller i germà del nostre autor, que custodie els assuts, a fi de garantir l'abastiment d'aigua i la molta de cereals, i es diu a la gent de batalla i mestres de camp de la ciutat de València què han de fer. Es traslladen al Cap i Casal les companyies de a cavall de Marcolfa, Canet, València, Horta d'Alacant i la de la Vila Joiosa. A més a més, els diputats comencen a repartir armes i municions a la Casa de les Armes, entre les persones que no en tenen. I als castellers se'ls ordena acudir a les seues fortaleses, per abastir-les i municionar-les. A Xàtiva, i altres pobles emmurallats, se'ls diu que tanquen les portes a calicanto; deixant-ne només algunes obertes amb gent de guarda y porta.

Aquest mateix dia, don Agustín Mexia, parteix amb dues galeres a Dénia per a organitzar l'embarcament que, com hom diu, començarà amb els moriscos de Dénia, Gandia i pobles del voltant.

L'endemà, 26 de setembre, arriba nova a València que uns 5.000 moriscos d'Alberic i d'Alcocer s'havien alçat i recollit a la serra del Cavalló. El virrei decideix perseguir-los i empresonar-los; però no condemnar-los a cap càstig fins que no s'hi hagués embarcat la resta d'habitants que quedaven d'aquelles poblacions. S'hi fa una altra crida demanant als cristians vells per tal que guardassen els camins dels seus pobles i no fessen dany als deportats. I per abundar amb les mesures de seguretat a València, es doblen les guardes al Real, al Portal Nou i les Torres de la Pólvora.

El 27 de setembre, l'arquebisbe Juan de Ribera fa una prèdica a la trona de la Seu en substància de la occació, impulsant els fidels a respectar les disposicions de la Crida. 
Josep Lozano. L'expulsió dels moriscos valencians, segons la Relació de Maximilià Cerdà de Tallada

El dia següent arriben noves a València que un bon nombre de moriscos s'ha refugiat a la serra d'Aitana, a la de Mariola, a Cortes de Pallàs i a Dos Aigües; però no a la serra d'Eslida, la qual, previngudament, ja estava ocupada per tropes del rei.

El primer d'octubre ix del port de Dénia, amb naus i galeres, la primera embarcació, amb més de 5.200 moriscos. I ens diu Cerdà de Tallada “...tots vells, dones y chichs; perquè tota la gent chove, amb dissimulació, a la desfilada y de nit, se retiraren a la muntanya”. També s'embarcaren al Grau de València moriscos dels pobles del voltant de la ciutat.

Amb data de 3 d'octubre, arribava nova a València sobre “...que 'n moltes parts avien mort y degollat molts moriscos, y que estaven per los camins a muntons. Y axí part que 's complí lo que el pronòstich deya dels efectes de la Confunció Magna...", perquè molta gent d'aleshores confiava amb els pronòstics astrològics i n'hi havia algun que augurava aquella matança i desterrament.

L'endemà diumenge, el 4 d'octubre, en hora de sermó, arriba a València la nova que ha hagut un gran avalot de moriscos a Burjassot, cosa que provoca gran commoció. Perquè hom deia que havien degollat la gent de tot aquell poble i que els avalotats eren 4000; altres deien que $1000 \mathrm{i}$ altres que 2000. Tot seguit, la por col lectiva féu que es tancaren moltes esglésies de la ciutat, com també portals, i començaren a voltejar campanes. Per bé que més tard va saber-se que no hi havia sigut tant: una renya de tres moriscos amb veremadors cristians $i$ on aquests havien mort un morisc $i$ fugiren. Després s'hi aplegaren 30 o 40 moriscos cercant venjança, mataren els tres veremadors i se'n tornaren a casa.

En els dies següents, don Pedro de Toledo anava amb 18 companyies de soldats de la mar, amb les companyies de la terra i de la milícia efectiva, a fi de dur moriscos a Vinaròs on hi havia l'esquadra de Nàpols i altres vaixells. N'embarcaren més de 5000, entre homes, dones i xics. També ens dóna Cerdà de Tallada dades sobre el Grau de València, on n'embarcaren 2.300, el que feia ja un total de 21.500 deportats. I del port d'Alacant, s'embarcaren en altres vaixells, així redons com de galeres, més de 8000 homes i dones, i també més de 1000 criatures de mamella.

El 8 d'octubre, els de Benilloba, Vall de Muro i altres llogarrets, fugen de les poblacions i es fan forts a la muntanya; però molts d'ells ja estaran en l'embarcador de Dénia 6 dies després, el 14 d'octubre.

L'11 del mateix mes, arriba al moll del Grau de València un vaixell dels que havien deportat moriscos rics a Berberia, que ells mateixos havien noliejat amb els seus diners. A Alacant s'embarcaren, en dita jornada, moriscos procedents d'Albatera, Crevillent, Asp, raval d'Elx, Novelda, Elda, Petrer, Salines i altres. En aquest mateix dia també ens diu Cerdà de Tallada que arribà al Grau de València un "vexell de volta -és a dir de tornada- dels que havien dexat allende moriscos".

El 14 d'octubre hi havia per a embarcar, al Grau de València, els dels pobles de Benimodo, Bunyol, Xest i Bétera, i també de l'Horta, com Picassent, Mirambells, Benimàmet i d'Alcàsser, el senyor 
Josep Lozano. L'expulsió dels moriscos valencians, segons la Relació de Maximilià Cerdà de Tallada

del qual, Pau Sanogera, serà el primer que durà els seus vassalls moriscos a l'embarcador. També arriben noves que tornen vaixells que havien fet ja la primera embarcació.

A Dénia se segueix embarcant moriscos de la Marina i de la Safor; al Grau de València, de pobles de la comarca de l'Horta i a Vinaròs de la serra d'Espadà, de Begís, la Vall de Segó i altres. En aquesta segona embarcació del Grau també hi havia moriscos de Xelva i raval, Calles, Tales, Benagéber i Benguany i els fugits a la serra del Cavalló, d'Alberic i Alcocer, que havien tornat a València per a embarcar-se.

Altrament, s'hi han creat dos focus de resistència a l'expulsió: Cortes, amb uns dos o tres mil moriscos, i al marquesat de Guadalest i valls de Laguar i Gallinera, on es calcula que hi ha uns sis o set mil.

Fet que Cerdà de Tallada explica de la següent manera: "molta part dels jòvens, per aver-se fet a montaña, no s'enbarcaren, retirant-se a quatre puestos forts", que són Guadalest, la vall de Laguar, la vall de Gallinera i Cortes. I que "tots los dits moriscos foren en número prop de vint-y-sinch mil jòvens, y les dones, chichs y vells, que en los pobles dels dits puestos se restaren”. Situació que causà "alguna inquietud y cuidado" a la població i autoritats cristianes, tot i que estaven molt mal armats. Perquè com també ens diu Cerdà de Tallada, només disposaven "de alguns pedranals y pistolets y alguns jusos llarchs, y de les relles y llegons que y avien fet fer als ferrers dels seus pobles, y moltes fones y alguns arcabussos, y pocs mosquests, ab los quals feyen vistes". 4

Tanmateix, els qui comandaven els exèrcits cristians creien que n'eren molts més, perquè els moriscos havien triat llocs de muntanya quasi inaccessibles per la seua orografia. A més, per enganyar l'enemic havien fet tambors amb bucs d'abelles i pells seques, com també un bon nombre de banderes amb llençols.

Situació bèl lica de la qual Maximilià Cerdà responsabilitza el virrei i el Consell d'Estat, per no haver avisat els senyors dels llocs moriscos de l'embarcament, i d'haver-ho fet cobert y dissimulat. Cosa que no havia passat el segle anterior en la revolta dels moriscos d'Espadà. I continua el cronista lamentant aquesta desconfiança, i falta de consideració, per part de les autoritats de la monarquia amb el braç militar valencià i amb tot el Regne, quan diu: "y aprés, com se à dit, y com serà, [ho] selaren, ${ }^{5}$ com dit és, dels señors de vassalls, y no sols d'ells, sinó de tota la nació valenciana".

Aleshores des de Xàtiva, don Agustín de Mexia, cap de l'exèrcit cristià, va dividir les seues forces en dos contingents, un per combatre els moriscos que es trobaven a Cortes i l'altre cap a Guadalest, on va anar ell personalment.

4 Desfilades o exploracions dels voltants per si hi havia enemics.

5 En el sentit 'd'amagar, d'ocultar'.

SCRIPTA, Revista internacional de literatura i cultura medieval i moderna, núm. 17 / juny 2021 / pp. 104-116 ISSN: 2340-4841 · doi:10.7203/SCRIPTA.17.20908 
Josep Lozano. L'expulsió dels moriscos valencians, segons la Relació de Maximilià Cerdà de Tallada

Al capdavall, els moriscos que s'havien fet forts a les muntanyes de la Marina van rendir-se i acceptaren l'embarcament, vençuts per la força numèrica cristiana $i$ la falta d'aigua $i$ abastiments. Cerdà ens conta aqueix final així: "Baxaren, otorgada la embarcació. De manera[que] fou un juí final veure'ls tan vençuts i transits, que arribats a la terra es rendiren gitats, sense forses; les dones sense tenir sos fillets que traure ni jupar de les mamelles de ses mares, pregant ab sos fills als soldats que ls prenguesen".

Els quals, els vençuts, malvengueren els seus béns immobles: ramat, roba, grans, garrofes, que tenien abans d'embarcar, $i$ ho hagueren de vendre tan barat que contà Cerdà que "quan han vengut a la embarcació no alcansaven per a menjar encara garrofes" . Perquè els especuladors cristians se n'aprofitaren i n'abusaren. Per exemple, diu Cerdà que a l'embarcador pagaven 3 sous (36 diners) el que abans costava només 2 diners. I que havent venut els moriscos la pansa i la figa a sou l'arrova, a l'embarcador, la lliura valenciana, la trentena part de l'arrova, es pagava a tres sous (36 vegades més), i un meló a sis sous.

Derrotats els moriscos de la Marina, l'altre focus a reconquerir pels cristians era Cortes, que era un lloc “aspre, perquè no s'i pot pujar sinó per dos parts y amb molts treballs, y abans d'arribar són moltes llegües de terra aspra y entre barrancs. Y se à de pasar lo riu Júquer -i llevaren lo pont estret de taules- lo qual pasa molt fondo per allí.”

A Cortes s'havien aplegat també moriscos de la Vall dels Alcalans, entre els quals l'alamí de Llombai, anomenat Cavallero, i el seu consogre, Vicent Turigi Sumaniar, de Catadau, a qui, "arribat que fonc a Cortes, lo nomenaren y alsaren per rey". El qual, que es deia descendent dels reis de Xativa, acceptà el càrrec i nomenà cavallers, secretari, mestres de camp i capitans. Des d'allí, el dit rei Turigi féu visites i ràtzies perquè es rebel laren els moriscos de Navarrés, l'Alcudieta, Quesa i Benedrix. I concretament a Navarrés tingué lloc un dels fets més cruels perpetrats pels moriscos, ja que en obligar el rector del poble que renegués de la fe cristiana i abracés la religió mahometana i negars'hi, ens diu el nostre cronista que "ab una axada li féu tallar los peus, les mans y brasos per les juntures y, fet trosos lo llançà en lo pou", Tampoc no hi volgué renegar del cristianisme l'algutzir, Jeroni Carci, d'origen morisc, a qui "per lo tos li pegaren un colp de mort, y 11 llansaren en lo pou, amb los demés que llansà, cristians vells". Actes violents que també es repetiren a Bicorp, on degollaren el senyor del lloc, don Pedro Luis de Soto, i mataren altres cristians vells.

Després, segons ens conta Cerdà de Tallada, Turigi tornà a Catadau, a sa casa, amb tres-cents moriscos. I "en sa casa, de davall d'un banc, que estava en una llogeta descoberta, tragué d'una xerreta que tenia allí, soterrats, més de 40.000 ducats de or, de moneda antiga morisca, i les s'emportà", per tal de finançar la guerra contra els cristians. Acte seguit se'n tornà a Cortes que ja estava millor fortificat.

6 El sistema monetari valencià tenia com a unitat de referència de moneda la lliura, com en tots els regnes de la Corona d'Aragó i Sardenya, basada en el seu pes en plata. Aquesta es dividia en 20 sous, i cada sou en 12 diners. De tal manera que una lliura equivalia a 240 diners. Pel que fa al pes, una arrova equivalia a 30 lliures valencianes. 
Josep Lozano. L'expulsió dels moriscos valencians, segons la Relació de Maximilià Cerdà de Tallada

Tanmateix, en una altra de les correries que feren els moriscos de Cortes, apressaren mossèn Gomes, a qui portaren davant del rei Turigi que li preguntà si volia ser cristià o moro, i aquest respongué que cristià, perquè era sacerdot. En acabant li digué si havia menjat i li va dir que no i el rei morisc li’n féu donar i menjà davant d'ell. Després li demanà si volia quedar-se a Cortes o anar-se'n, i mossèn Gomes li respongué que tornar-se'n volia si li donava llicència. I conta Cerdà de Tallada que Turigi "digue-li que si, perquè pogués contar com era també rey benigne".

Aleshores féu que l'acompanyaren un bon tros de camí per a deixar-lo en lloc segur, però abans li donà dues cartes: una per a l'arquebisbe Ribera, de la qual no saben el contingut, i una altra per al governador de Xàtiva, dient-li que "li manava que dins tres dies li entregàs la ciutat y el castell, sinó ho pasarien tot a foch y sanhc, perquè a ell li pertañia, com a descendent de aquells reis".

Però abans d'atacar l'exèrcit cristià Cortes, el virrei li envià a Turigi, com a emissari, Lloís Jofré, cavaller de l'Orde de Montesa, comanador de Montroi, i que coneixia ${ }^{7}$ molt el rei morisc, per a intercedir en la rendició dels moriscos. I tot i que Jofre hi anà, tornà sense haver acordat res. És ben significatiu el que ens conta el nostre cronista d'aquest encontre entre el cavaller Jofré i el rei Turigi: "Lo qual lo rebé ab sitial, y posada en alt una cadira, y vestit amb roba de domàs carmesí, y féu donar una cadira allí bax."

Posteriorment, l'exèrcit cristià va marxar a conquerir Cortes guiat pel cavaller Francesc Bou, germà del senyor del poble de Millars, on s'hi havia criat i era bon coneixedor d'aquella terra. El qual, per ser l'orografia del camí a Cortes tan aspra y tan trencada, féu que la logística militar hi previngués, per a la tropa cristiana que es desplaçava, moltes espardenyes, i per la cavalleria moltes ferradures. Exèrcit que va passar per la Mola del Oro de Bicorp i més amunt van creuar el riu Xúquer i arribaren a les envistes de Cortes sense trobar cap resistència. Acte seguit acamparen els esquadrons a certa distància del poble, tot fent gran ostentació de recursos bèl lics i de banderes. En acabant s'hi digué un ban exigint als moriscos que "dins de breu temps y espay se rendissin los perros -terme pejoratiu amb què designaven els cristians els musulmans- o els pasarien a foch $y$ sanc."

Fins que baixà del poble de Cortes una representació morisca que acordà amb els cristians parlamentar, l'endemà, dels termes de la rendició a la casa dels Pedriscos, en que hi assistiren sis membres per cada part. Pels cristians anirien el governador de Xàtiva, don Francisco Milà i don Francesc Bou i tres capitans del Terç de Llombardia. En la reunió del dia següent, en què només assistiren tres moriscos, s'assentà que ells acceptaven embarcar-se, però que demanaven tres dies per a vendre els seu béns. I que després abandonarien primer les poblacions de Cortes i de Boixet, i tres hores després Roaia. Però el mestre de camp del Terç de Llombardia, don Juan de Córdoba, i els seus terços, no respectaren el que s'havia pactat i saquejaren Roaia.

\footnotetext{
7 Atés que els termes de Montroi i del marquesat de Llombai, que inclou el poble de Catadau, on procedia Turigi, són limítrofs.
} 
Josep Lozano. L'expulsió dels moriscos valencians, segons la Relació de Maximilià Cerdà de Tallada

Fet que provocà que Turigi, en saber-ho, fugira amb la família i mil seguidors amb diners i bagatges. La resta de la població morisca, sobretot dones i xiquets, marxaren cap a Xàtiva on els distribuïren per embarcar-los a València, Dénia i Alacant. Deixaren amagats o no, en cases i coves, a més de bagatges, quatre mil cafissos ${ }^{8}$ de forment o blat $i$ altres grans i més de quinze mil caps de ramat oví i caprí $i$ algunes vaques.

Altrament, Turigi va acovilar-se amb els seus a Dos Aigües, però l'exèrcit cristià els atacà i cremà les cases de la població, en una de les quals es trobava la mare malalta del rei morisc, que va morir cremada. Després fugí cap al seu poble d'origen, Catadau, on s'amagà en una cova per la qual s'entrava per un forat que hi havia entre les arrels d'una carrasca, en una partida del terme que actualment encara es diu Turigi. Però detingueren i turmentaren Cavallero, el seu consogre, que delatà l'amagatall del rei fugit, i el senyor de Carlet va apressar-lo. El qual el dugué al Palau Reial de València, des d'on el passaren a les torres de Serrans.

Dies després el jutjaren i el sentenciaren a ser tenallat amb eines roents, tallar-li la mà dreta, les orelles i, finalment, esquarterar-lo. Tot i que abans de l'execució, Turigi pactà -amb un dominic, fra Jeroni Alcocer, segons el Llibre d'Antiquitats (Martí 1994, I: 272, que indica que la condemna tingué lloc el 16 de desembre de 1609) o amb caputxí, segons Cerdà de Tallada- per a que, barat a batejar-se, el dugueren ja mort al turment, per no sofrir tant; com així va succeir. Finalment, després de fer-los quarts, posaren en una gàbia de ferro, penjada al portal de Sant Vicent, el seu cap coronat amb una corona de ferro al revés. ${ }^{9}$

En els dos darrers folis de la Relació, Cerdà de Tallada ens parla del problema dels censals i del batiment de moneda falsa. I acaba referint-se a la inoperància del sistema foral, representat pels tres braços o estament, davant del poder reial. Quan lacònicament diu: "Y ayxí may y agué compliment y efecte dels braços, del modo que se à pres de l'expulsió dels moros”.

Més tard serà convocat en l'última junta de censalistes, petits i gran inversors, que veuen perillar els seus interessos amb les seqüeles que s'hi albiren d'aquella “depopulació". Per altra banda, el nostre autor ens dóna, en aquest text, una xifra sobre el nombre de pobles de moriscos que hi havien embarcat, que va ser de 453. Per a un dels estudiosos del tema, Henri Lapeyre (1986), podrien ser uns 117.000 moriscos els foragitats valencians, que representaven entre un 33 o $34 \%$ de la població total del Regne de València d'aleshores.

Finalment dir que aquest és l'únic text que es coneix en català de l'expulsió dels moriscos valencians. I que tot i que l'autor, Maximilià Cerdà de Tallada, no té una gran rellevància com a literat, ni com a home públic, la seua Relació de fets és un testimoni directe, ocular i, per tant, una font d'informació de primera mà, en què ell n'és un protagonista actiu. El qual, a més, ens forneix unes dades i fets gens menyspreables, que fan que la Relació tinga un remarcable interés.

8 Unitat de mesura de capacitat per a sòlids. Un cafís equivalia a 4 quarteres i 24 barcelles és a dir, 2,01 hl.

9 Per a significar que era un rei fals. Vegeu, també Porcar (2012: 214-215).

SCRIPTA, Revista internacional de literatura i cultura medieval i moderna, núm. 17 / juny 2021 / pp. 104-116 ISSN: 2340-4841 ·doi:10.7203/SCRIPTA.17.20908 
Josep Lozano. L'expulsió dels moriscos valencians, segons la Relació de Maximilià Cerdà de Tallada

\section{Bibliografia}

Císcar Pallarés, Eugenio (2010). "La vida material de los moriscos del Reino de Valencia. Notas y reflexiones sobre el estado de la cuestión”, Estudis, 35, pp. 37-84.

Lapeyre, Henri (1986). Geografía de la España morisca. València: Institució Alfons el Magnànim.

Lozano, Josep (2001). "La Relació verdadera de Maximilià Cerdà de Tallada", Caplletra, 31, pp.4174.

Martí Mestre, Joaquim (ed.). (1994) El Llibre d'Anquitats de la Seu de València. València / Barcelona: Institut Universitari de Filologia Valenciana - Publicacions de l'Abadia de Montserrat. 2 vols.

Porcar, Pere Joan Porcar (2012). Coses evengudes en la ciutat y regne de València. Dietari (1585-1629), València: Publicacions de la Universitat de València. 2 vols.

Ximeno, Vicent (1747-1749). Escritores del reyno de València. València: Josep Esteban Dolz, 2 vols. 